\title{
The role of disulfide bond in hyperthermophilic endocellulase
}

\author{
Han-Woo Kim • Kazuhiko Ishikawa
}

Received: 10 January 2013/Accepted: 11 April 2013/Published online: 27 April 2013

(C) The Author(s) 2013. This article is published with open access at Springerlink.com

\begin{abstract}
The hyperthermophilic endocellulase, EGPh (glycosyl hydrolase family 5) from Pyrococcus horikoshii possesses 4 cysteine residues forming 2 disulfide bonds, as identified by structural analysis. One of the disulfide bonds is located at the proximal region of the active site in EGPh, which exhibits a distinct pattern from that of the thermophilic endocellulase EGAc (glycosyl hydrolase family 5) of Acidothermus cellulolyticus despite the structural similarity between the two endocellulases. The structural similarity between EGPh and EGAc suggests that EGPh possesses a structure suitable for changing the position of the disulfide bond corresponding to that in EGAc. Introduction of this alternative disulfide bond in EGPh, while removing the original disulfide bond, did not result in a loss of enzymatic activity but the EGPh was no longer hyperthermostable. These results suggest that the contribution of disulfide bond to hyperthermostability at temperature higher than $100{ }^{\circ} \mathrm{C}$ is restrictive, and that its impact is dependent on the specific structural environment of the hyperthermophilic proteins. The data suggest that the structural position and environment of the disulfide bond has a greater effect on high-temperature thermostability of the enzyme than on the
\end{abstract}

Communicated by A. Driessen.

\section{H.-W. Kim}

Division of Life Sciences, Korea Polar Research Institute (KOPRI), Incheon 406-840, Korea

\section{K. Ishikawa ( $\square)$}

Biomass Refinery Research Center, National Institute of Advanced Industrial Science and Technology (AIST), 3-11-32 Kagamiyama, Higashi-Hiroshima,

Hiroshima 739-0046, Japan

e-mail: kazu-ishikawa@aist.go.jp potential energy of the dihedral angle that contributes to disulfide bond cleavage.

Keywords Disulfide bond - Cellulase - Archaea . Thermostability · Crystal structure · Protein engineering

\section{Introduction}

During the past decade, many researchers have attempted to develop an optimized enzyme that possesses high activity and stability suitable for industrial processes. Enzymes from hyperthermophiles have shown promising candidates for industrial applications because of their intrinsic thermal and chemical stability. The crystal structure of hyperthermophilic beta-1,4 endocellulases (EGPh, glycosyl hydrolase family $5, T_{\mathrm{opt}}=100{ }^{\circ} \mathrm{C}$ ) from the archaeon Pyrococcus horikoshii, that was isolated from an oceanic hydrothermal volcanic vent, has been determined (Kim and Ishikawa 2010).

EGPh exhibits high structural similarity to the thermophilic beta-1,4 endocellulase (EGAc, glycosyl hydrolase family $5, T_{\mathrm{opt}}=81{ }^{\circ} \mathrm{C}$ ) from Acidothermus cellulolyticus. Information regarding the structure of an enzyme greatly helps to understand its biophysical properties, such as thermostability. Typically, there are few disulfide bonds in hyperthermophilic proteins (Ladenstein and Ren 2008). Furthermore, disulfide bond stability might not be compatible with the high temperature of $100{ }^{\circ} \mathrm{C}$ (Volkin and Klibanov 1987). In the superimposed structure of EGPh and EGAc, the disulfide-bonding pattern of both enzymes was different despite their nearly identical structures. One of the disulfide bonds of EGPh is located at a region near the active site cleft, which is likely to be important for enzymatic activity, as well as for thermostability. 
Therefore, we investigated the functional role of the disulfide bond in EGPh using X-ray crystallographic and mutational analyses.

\section{Materials and methods}

Construction and preparation of the mutant enzymes

The EGPh $\Delta \mathrm{N} 5 \mathrm{C} 5$ gene which is the truncated mutant gene lacking 5 amino-acid residues from the $\mathrm{N}$ - and $\mathrm{C}$-terminal ends of EGPh was used as template for mutational analysis (Kim and Ishikawa 2010). Point mutant enzymes were prepared using site-directed mutagenesis following the Quick-Change Mutagenesis method (Stratagene, CA, USA). All mutant genes were inserted into the expressionvector pET11a (Novagen, Madison, WI, USA). The constructed plasmids were introduced into Escherichia coli strain BL21(DE3) for recombinant protein expression. Expression and purification of the recombinant enzymes was carried out following the method reported previously
(Kim et al. 2007; Kim and Ishikawa 2011). The purity and molecular weight of the protein sample were analyzed by SDS-PAGE. The protein concentration of the enzyme was determined from UV absorbance at $280 \mathrm{~nm}$, using 134,990 as the molar extinction coefficient calculated from their protein sequences, respectively.

Activity measurement

The hydrolytic activity of the enzymes toward phosphoric acid swollen avicel (PSA) (Wako Pure Chemicals) was determined by measuring the amount of the released reducing sugars with the modified Somogyi-Nelson method (Hiromi and Ono 1963; Kim and Ishikawa 2011) at $85{ }^{\circ} \mathrm{C}$ in $100 \mathrm{mM} \mathrm{Na}$ /acetate buffer (pH 5.5).

\section{Crystallization}

The purified proteins were dialyzed against $50 \mathrm{mM}$ Tris$\mathrm{HCl}$ buffer (pH 8.0) and then concentrated to $10 \mathrm{mg} \mathrm{ml}^{-1}$. Crystallization was performed using the hanging-drop
Table 1 Statistics of data collection and refinement

Values for the last resolution shell are given in parentheses

${ }^{\mathrm{a}} R_{\text {merge }}=\sum_{\mathrm{hkl}} \sum_{i} \mid I_{i}(\mathrm{hkl})-$ $<I(\mathrm{hkl})>\mid \sum_{\mathrm{hkl}} \sum_{i} I_{i}(\mathrm{hkl})$, where $I_{i}(\mathrm{hkl})$ is the $i$-th intensity measurement of reflection hkl, including symmetry-related reflections, and $\langle I(\mathrm{hkl})>$ is their average

${ }^{\mathrm{b}} R_{\text {work }}=\sum_{\mathrm{hkl}} \mid F_{\mathrm{o}}-F_{\mathrm{c}} \mathrm{l} / \sum_{\mathrm{hkl}}$ $F_{\mathrm{o}}$ where $F_{\mathrm{o}}$ and $F_{\mathrm{c}}$ are the observed and calculated structure factor amplitudes of reflection hkl, respectively

c $R_{\text {free }}$ is calculated as the $R_{\text {cryst }}$, using $F_{\mathrm{o}}$ that was excluded from the refinement (5\% of the data)

\begin{tabular}{|c|c|c|}
\hline & Wild type & P74C \\
\hline \multicolumn{3}{|l|}{ Data collection } \\
\hline Wavelength $(\AA)$ & 0.9 & 0.9 \\
\hline Space group & $C 121$ & $C 121$ \\
\hline Unit-cell parameters $(\AA)$ & $\begin{array}{l}a=161.10, b=58.34, c=137.92 \\
\quad \beta=109.65\end{array}$ & $\begin{array}{l}a=160.24, b=58.68 \\
c=138.54 \\
\beta=108.93\end{array}$ \\
\hline Matthews coefficient $\left(\AA^{\mathrm{c}} \mathrm{Da}^{-1}\right)$ & 2.35 & 2.37 \\
\hline Solvent content $(\%)$ & 47.68 & 48.16 \\
\hline Subunits per asymmetric unit & 3 & 3 \\
\hline Resolution range $(\AA)$ & $50-1.75(1.81-1.75)$ & $50-1.95(1.98-1.95)$ \\
\hline Number of observed reflections & 457,155 & 385,303 \\
\hline Total number of unique reflections & 121,695 & 89,041 \\
\hline Redundancy & $3.8(3.2)$ & $4.4(4.1)$ \\
\hline$<I / \sigma(I)>$ & $37.9(5.0)$ & $20.3(6.4)$ \\
\hline$R_{\text {merge }}^{\mathrm{a}}$ & $0.073(0.434)$ & $0.085(0.305)$ \\
\hline Completeness $(\%)$ & $98.7(87.5)$ & $99.5(98.5)$ \\
\hline \multicolumn{3}{|l|}{ Refinement } \\
\hline Resolution used in refinement & $44.69-1.75(1.77-1.75)$ & $34.52-1.95(1.97-1.95)$ \\
\hline$R_{\text {work }}^{\mathrm{b}}(\%)$ & $17.6(27.4)$ & $15.4(15.3)$ \\
\hline$R_{\text {free }}^{\mathrm{c}}(\%)$ & $20.5(31.6)$ & $18.8(22.7)$ \\
\hline R.M.S. bond distance $(\AA)$ & 0.007 & 0.007 \\
\hline R.M.S. bond angle $\left(^{\circ}\right)$ & 1.072 & 1.083 \\
\hline Mean overall $B$ factor $\left(\AA^{b}\right)$ & 23.99 & 15.61 \\
\hline \multicolumn{3}{|l|}{ Ramachandran plot } \\
\hline In favored regions (\%) & 98.1 & 98.0 \\
\hline In disallowed regions $(\%)$ & 0.0 & 0.0 \\
\hline PDB ID & $3 \mathrm{~W} 6 \mathrm{~L}$ & $3 \mathrm{~W} 6 \mathrm{M}$ \\
\hline
\end{tabular}


vapor-diffusion method. The drops consisted of equal volumes $(1.5 \mu \mathrm{l})$ of the protein and reservoir solutions. The crystal of the enzymes was prepared using a reservoir solution consisting of $1.5 \mathrm{M}$ ammonium phosphate and 0.1 M MES buffer ( $\mathrm{pH}$ 6.5). The crystals were obtained over a period of $\sim 3$ days at $22{ }^{\circ} \mathrm{C}$.

Data collection and processing

The crystals were collected with a Cryo-loop (Hampton Research, Aliso Viejo, CA, USA) and immediately flashcooled at $100 \mathrm{~K}$ in a nitrogen cryostream. Diffraction data of the crystals were collected at BL44, SPring-8 (Harima, Hyogo, Japan), and processed and scaled using the HKL2000 and CCP4 package (CCP4 1994). The structure of the mutant enzyme was solved by molecular replacement using Molrep program implemented in CCP4 package. Refinement of the structures was performed with REFMAC5 in CCP4 package and Phenix.refine in the PHENIX package. All model building-stages were performed with the coot program (Emsley and Cowtan 2004). The diffraction data statistics and the crystallographic refinement statistics are summarized in Table 1. Figures were produced using PyMOL program (http://www.pymol.org).

\section{Differential scanning calorimetry}

Differential scanning calorimetry (DSC) measurements were carried out using a nanoDSCII instrument (TA Instruments, DE, USA) with platinum tubing cells with a volume of $0.3 \mathrm{ml}$. Proteins were dialyzed against Na/acetate $50 \mathrm{mM}$ (pH 5.5). The dialysate buffer was used as a reference solution for the DSC scanning. Samples containing $1.0 \mathrm{mg} / \mathrm{ml}$ of protein were heated at $1{ }^{\circ} \mathrm{C} / \mathrm{min}$ from 5 to $125{ }^{\circ} \mathrm{C}$.

\section{Results}

Structural comparison of disulfide bonds of EGPh and EGAc

EGPh is a family 5 hyperthermophilic glycosyl hydrolase $\left(T_{\mathrm{opt}}=100^{\circ} \mathrm{C}\right)$. The crystal structure of EGPh revealed 4 Cys residues (C106, C159, C372, and C412) forming 2 disulfide bonds. The disulfide bonding of C106 and C159 forms at the end of the loop associated with the substratebinding active site cleft (Fig. 1). The other bond appears to be located at the C-terminal region, although it could be not observed in the crystal structure owing to the absence of C412 in the truncated mutant used for protein crystallization. EGAc is a family 5 thermophilic glycosyl hydrolase
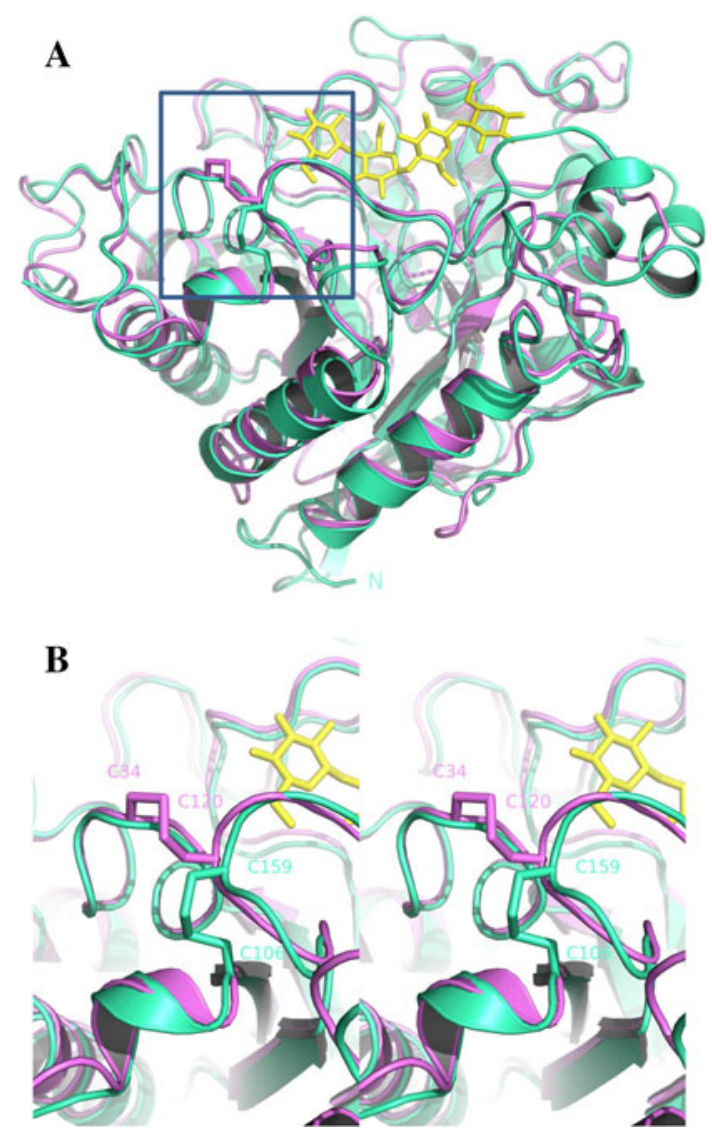

Fig. 1 Comparison of the overall structure from P. horikoshii EGPh (magenta) and A. cellulolyticus EGAc (light green) (a) and close-up cross-eyed stereo view of the structure of the disulfide bonds in EGPh and EGAc (b). The cellotetraose from the EGAc-ligand complexed structure (PDB code: 1ECE) is denoted by yellow color

$\left(T_{\text {opt }}=81^{\circ} \mathrm{C}\right)$. Both enzymes belong to family 5, subfamily 1 cellulases (Kim and Ishikawa 2010), and resent sequence analysis has revealed putative disulfide-bonding Cys residues at the active cleft loop in a few homologs (data not shown). The superimposed structure of EGPh and EGAc demonstrates that $\mathrm{C} 159$ in EGPh is conserved in EGAc (C120) (Fig. 1b) but the pattern of the disulfide bond of EGPh (C106-C159) is different from that of EGAc (C34-C120) (Fig. 1).

Construction and structural analysis of mutants

The three-dimensional structural positions for the residues (P74, C106, C159) in EGPh are close to those for the residues (C34, S66, C120) in EGA (Fig. 1). However, the pattern of the disulfide bond of EGPh (C106-C159) is different from that of EGAc (C34-C120) (Fig. 1). Therefore, it is assumed that alternative disulfide bond can be introduced between P74 and C159 in EGPh. Given that the disulfide bond (C106-C159) is located too close to the active cleft in EGPh (Fig. 1b), we assumed that a 

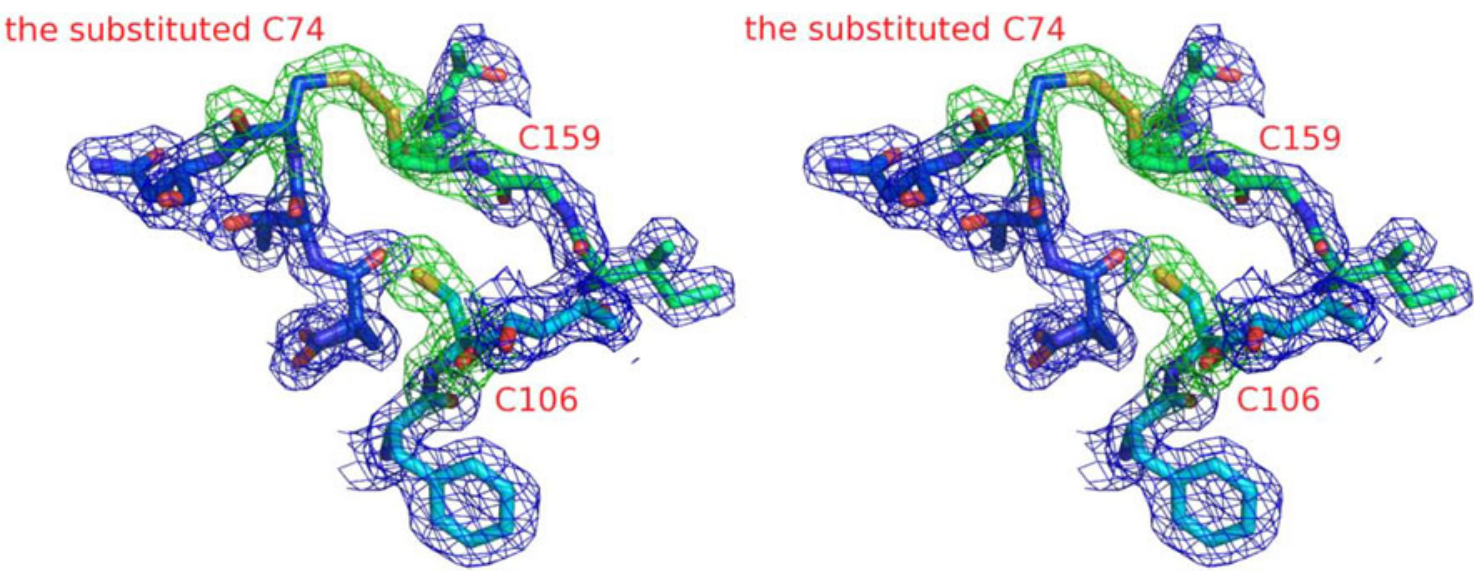

Fig. 2 Cross-eyed stereo view of $2 F_{\mathrm{o}}-F_{\mathrm{c}}$ (blue) and $F_{\mathrm{o}}-F_{\mathrm{c}}$ (green) positive electron density in the omit map of P74C. The $F_{\mathrm{o}}-F_{\mathrm{c}}$ omit map (contour level: $3.0 \sigma$ ) was calculated prior to incorporation of 3 Cys residues in the structure model

conformational change of the region encompassing the disulfide bond might affect enzyme activity. To investigate a role of the disulfide bond in the activity and stability of the enzyme, we prepared 3 mutants of EGPh; P74C, $\mathrm{C} 106 \mathrm{~S}$, and $\mathrm{P} 74 \mathrm{C} / \mathrm{C} 106 \mathrm{~S}$, in which we removed the disulfide bond or changed the disulfide-bonding pattern. Based on the superimposed structures of EGPh and EGAc, the position of P74 in EGPh corresponding to C34 in EGAc involves the disulfide bond (C34-C120) in EGAc (Fig. 1b). Therefore, the position of P74 might be forming the disulfide bond to $\mathrm{C} 159$ in EGPh. The mutant C106S has only 1 Cys residue (C159); thus, disulfide bond cannot form around this site in EGPh. The mutant P74C/C106S possesses 2 Cys residues at the region and is expected to form a disulfide bond (C74-C159) structurally similar to that of EGAc (C34-C120). In the mutant P74C, we paid particular attention to which pair of residues among the 3 Cys residues (C74, C106, and C159) would participate in disulfide bond formation in EGPh. To visually confirm a disulfide bond in $\mathrm{P} 74 \mathrm{C}$, we prepared the $\mathrm{P} 74 \mathrm{C}$ protein crystal using the condition described in "Materials and methods" and solved the crystal structure of P74C at a resolution of $1.95 \AA$ (Table 1) (PDB ID: 3W6M). Figure 2 shows the structure model and the $F_{\mathrm{o}}-F_{\mathrm{c}}$ omit map around the 3 Cys residues in $\mathrm{P} 74 \mathrm{C}$. The structural data demonstrated that the substituted $\mathrm{C} 74$ residue formed a new disulfide bond (C74-C159) (Fig. 2). The newly formed disulfide bond (C74-C159) in EGPh was located at the conserved position for the disulfide bond (C34-C120) in EGAc (Fig. 1). The conformation of the newly formed disulfide bond in EGPh also exactly matched with that of EGAc on the superimposed structure. The neighboring residues around the Cys residues were not affected structurally by the mutation (Fig. 1). Moreover, as expected, the P74C/C106S mutation possesses an identical disulfide

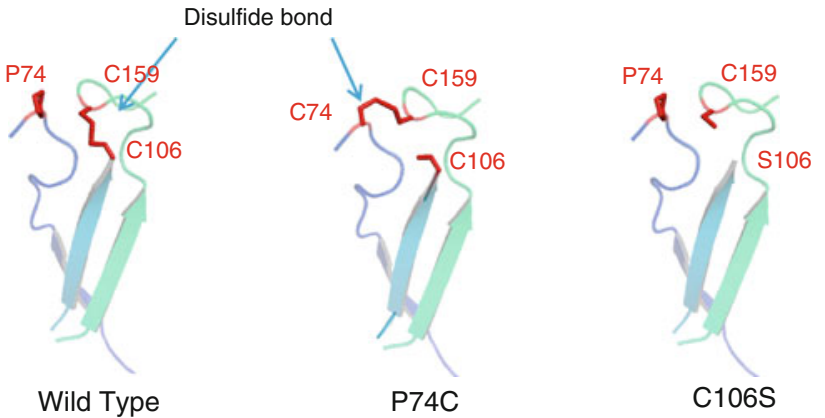

Fig. 3 Comparison of the disulfide bonds from the mutants and wild type. P74C with 3 Cys residues showed an identical disulfide-bonding pattern to EGAc. C106S has no disulfide bond

bond (C74-C159) conserved in EGAc. These results indicate that the formation of the disulfide bond at positions (C74-C159) is structurally stable in the folding process of EGPh. Figure 3 shows the comparison of the disulfide bonds from the mutants and wild type. The structure of $\mathrm{P} 74 \mathrm{C}$ with $3 \mathrm{Cys}$ residues obtained from the crystal structural analysis (PDB ID: $3 \mathrm{~W} 6 \mathrm{M}$ ) showed an identical disulfide-bonding pattern to EGAc. The structure of C106S without disulfide bond (Fig. 3) was the model constructed from wild type. We calculated the potential energy of the disulfide bonds in the enzymes. In the disulfide bonds of the wild type and $\mathrm{P} 74 \mathrm{C}$, internal dihedral angles are approximately $+90^{\circ}$, forming a typical right-handed hook conformation (Creighton 1988). Theoretical dihedral energies of disulfide configuration were calculated ignoring any possible influences of the residues around the disulfide bond. As shown in Table 2, the dihedral strain energy (DSE) (Schmidt et al. 2006) of C106-C159 in the wild type is slightly higher than that of C74-C159 in P74C. 
Table 2 Comparison of the geometry and potential energy of the disulfide bond on the structures of wild type and the mutant P74C

\begin{tabular}{|c|c|c|c|c|c|c|c|c|c|}
\hline Enzymes & S-S bond & $\mathrm{Mol}^{\mathrm{a}}$ & $\chi_{1}$ & $\chi_{2}$ & $\chi_{3}$ & $\chi_{2}^{\prime}$ & $\chi_{1}^{\prime}$ & $\operatorname{DSE}\left(\mathrm{kJ} \mathrm{mol}^{-1}\right)^{\mathrm{b}}$ & $\mathrm{C}_{\alpha}-\mathrm{C}_{\alpha}(\AA)$ \\
\hline \multirow[t]{3}{*}{ WT } & \multirow[t]{3}{*}{ C106-C159 } & A & 60.9 & 148.8 & 85.1 & -89.8 & -50.3 & 11.7 & 5.7 \\
\hline & & B & 58.0 & 150.4 & 84.3 & -89.6 & -52.5 & 10.9 & 5.7 \\
\hline & & $\mathrm{C}$ & 64.9 & 148.6 & 79.6 & -90.4 & -53.5 & 11.7 & 5.7 \\
\hline \multirow[t]{3}{*}{ P74C } & \multirow[t]{3}{*}{ C74-C159 } & A & -58.9 & -51.0 & 89.8 & 99.8 & 60.4 & 9.2 & 5.0 \\
\hline & & B & -64.5 & -46.1 & 88.3 & 91.9 & 62.2 & 8.3 & 5.1 \\
\hline & & $\mathrm{C}$ & -55.9 & -53.4 & 88.6 & 89.8 & 57.2 & 7.0 & 5.0 \\
\hline
\end{tabular}

The five $\chi$ angles of the disulfide bond are represented as the below

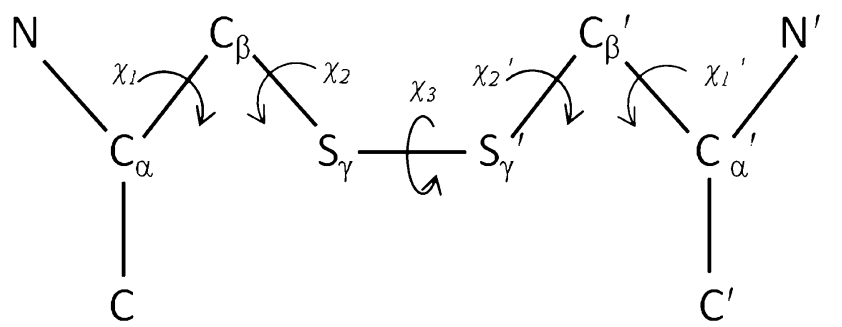

a This protein crystal contains the 3 molecules in the symmetric unit

b The dihedral strain energy (DSE) of the disulfide was calculated using the following empirical formula (Schmidt et al. 2006)

$\operatorname{DSE}\left(\mathrm{kJ} \mathrm{mol}^{-1}\right)=8.37\left(1+\cos 3 \chi_{1}\right)+8.37\left(1+\cos 3 \chi_{1}{ }^{\prime}\right)+4.18\left(1+\cos 3 \chi_{2}\right)+4.18\left(1+\cos 3 \chi_{2}{ }^{\prime}\right)+14.64\left(1+\cos 2 \chi_{3}\right)+2.51(1+$ $\left.\cos 3 \chi_{3}\right)$

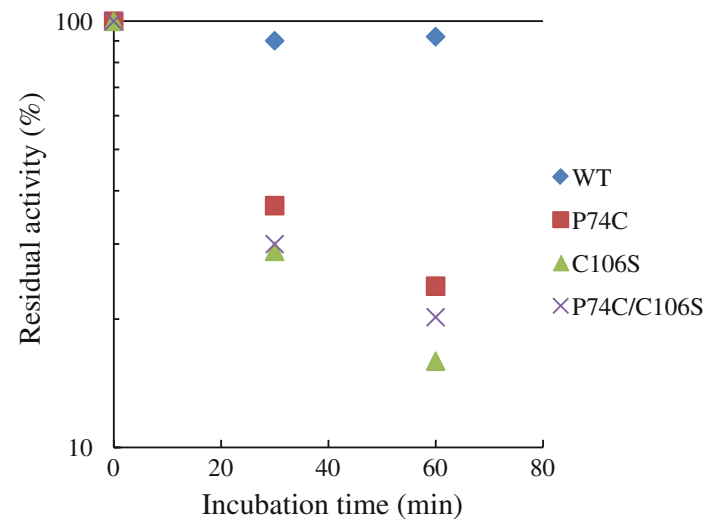

Fig. 4 Thermostability of wild type and the mutants examined by measuring the residual activity after heat treatment. Heat treatment of the proteins $(1.5 \mu \mathrm{M})$ was performed at $95{ }^{\circ} \mathrm{C}$ for each incubation time, and chilled immediately on ice. The residual activity was measured by detecting reducing sugar released from CMC

Thermal analysis of the mutants

The mutants were examined for their activity using PSA. No significant change in the enzymatic activity at $80{ }^{\circ} \mathrm{C}$ was observed between the mutants and the wild type (data not shown), suggesting that the region involving the disulfide bond did not significantly influence substratebinding or catalysis. To investigate the effects of disulfide bonds on irreversible thermostability, we determined the residual activity after heat treatment. As shown in Fig. 4,

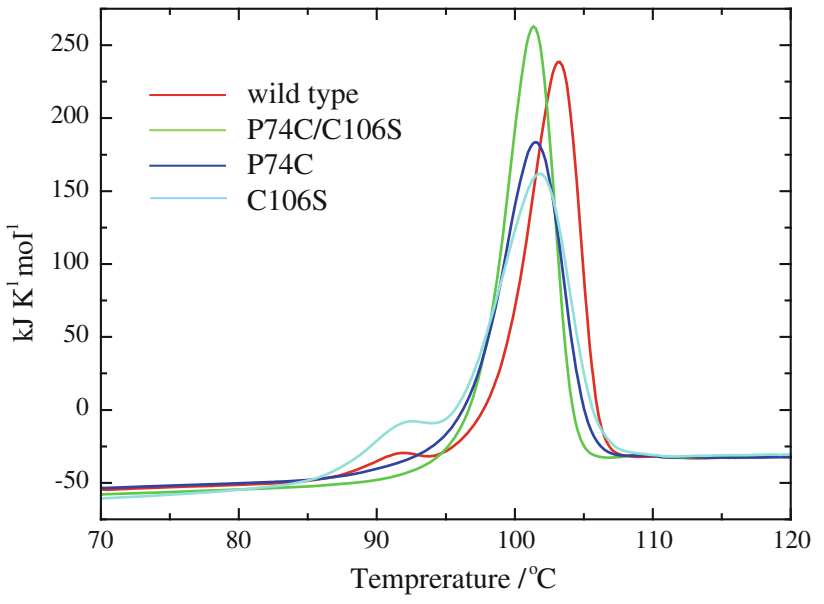

Fig. 5 Differential scanning calorimetry (DSC) profiles of wild type and the mutants in $50 \mathrm{mM}$ sodium acetate buffer ( $\mathrm{pH} 5.5$ )

all of the mutants showed a dramatic decrease in residual activity after heat treatment compared with the wild type. Furthermore, we determined the melting temperature $\left(T_{\mathrm{m}}\right)$ of the wild type and the mutant enzymes using DSC. The wild type enzyme was thermally unfolded at $103.4{ }^{\circ} \mathrm{C}$. The melting temperature of the 3 mutants was approximately $101.5^{\circ} \mathrm{C}$ (Fig. 5). These results indicate that the alternative new disulfide-bonding pattern involved in the position of P74 did not contribute to its hyperthermostability. We concluded, therefore, that only the disulfide-bonding 
pattern (C106-C159) in the wild type plays a role in enzyme stability in a hyperthermic environment.

\section{Discussion}

Sequence analysis and structural comparison between EGPh and EGAc showed that they have distinct disulfide bond conformations in the variable region linked to the substrate-binding cleft, even though these two enzymes are both family 5 subfamily 1 cellulases. The Cys residues involved in disulfide bond formation are generally believed to be conserved among related homolog proteins (Overington et al. 1993; Richardson 1981). However, our recent analysis revealed that disulfide bond patterns are not necessarily conserved among homologues. Poorly conserved disulfide bonds were found mainly in the variable region, and they tend to stabilize the protein structure of the variable region (Rigden et al. 2011).

The crystal structural analysis of EGPh mutants revealed that a new disulfide bond at the position of P74 is formed in P74C and P74C/C106S. The structure of P74C with 3 Cys residues near the active site showed the same disulfidebonding pattern as that of EGAc, suggesting that the conserved C159 prefers a linkage with the substituted C74 rather than with $\mathrm{C} 106$, unlike that of the wild type. Disulfide bond formation requires a strict stereochemical configuration. The angle between the sulfide and $\mathrm{C}_{\beta}$ atom of each Cys residue must be close to $103^{\circ}$, and the dihedral angle ( $\chi_{3}$ in Table 2) of the $2 \mathrm{C}_{\beta}$ atoms involved in disulfide bond must correspond to either $+90^{\circ}$ (right-handed) or $-90^{\circ}$ (left-handed) (Creighton 1988). In the structures of the wild type and P74C, the disulfide bonds have a near optimal geometry for the bond angle as well as the dihedral angle. When comparing redox potential, the disulfide bond in C74-C159 (P74C) possesses lower DSE than that in $\mathrm{C} 106-\mathrm{C} 159$ (wild type). The $\mathrm{C}_{\alpha}-\mathrm{C}_{\alpha}$ distance (5.0 $)$ of $\mathrm{C} 74-\mathrm{C} 159$ was also slightly closer $(5.7 \AA)$ than that of C106-C159 (Table 2). These structural factors may allow the conserved residue $\mathrm{C} 159$ to easily form a disulfide bond with the substituted $\mathrm{C} 74$ rather than $\mathrm{C} 106$ of the wild type. Disulfide bonds with high potential energy are more easily cleaved than bonds with lower energy (Schmidt et al. 2006). However, the thermal analysis indicates that the C106-C159 bond with higher potential energy contributes to thermostability while the $\mathrm{C} 74-\mathrm{C} 159$ bond has no role in stability. This inconsistency and the stabilizing effect of the disulfide bond could be explained by the position of Cys residues. The residues $\mathrm{C} 74$ and $\mathrm{C} 159$ are located along flexible loop, and the position of $\mathrm{C} 106$ is located within a rigid region of strand structure (Fig. 3). Cross-linking via a disulfide bond with the rigid residue $\mathrm{C} 106$ may increase the rigidity of the flexible region involving the counterpart residue $\mathrm{C} 159$, resulting in increased conformational stability that affects thermostability (Fig. 3). The conformational differences in disulfide bonding between EGPh and EGAc imply that the $P$. horikoshii enzyme acquired (or retained) a disulfide bond conformation that increased its stability to extreme environmental conditions. The disulfide bond in the wild type plays a role in its stability on the hyperthermic environment. The introduction of the disulfide bond to the flexible region of the enzymes with higher DSE might be the strategy for maintain hyperthermostability of hyperthermophilic enzyme. The contribution of the disulfide bond toward thermostability in the wild type was not consistent with temperature over $100{ }^{\circ} \mathrm{C}$, a temperature at which the host $P$. horikoshii survives, because the upper limit of disulfide bond stability has been believed to be $100{ }^{\circ} \mathrm{C}$ (Volkin and Klibanov 1987). This notion for susceptibility of disulfide bond is based on early studies to characterize protein inactivation mechanisms of mesophilic enzymes that were available at that time. Recent research on thermostable enzymes revealed that their disulfide bonds can protect against denaturation even above $100{ }^{\circ} \mathrm{C}$ (Cacciapuoti et al. 1994; Choi et al. 1999; Toth et al. 2000).

To improve the stability of an enzyme, one of the most commonly used technique in protein engineering is to introduce disulfide bond. However, only a few such cases have resulted in increased stability of the altered proteins relative to that of the wild-type protein (Han et al. 2009; Mansfeld et al. 1997; Mansfeld and Ulbrich-Hofmann 2007; Turunen et al. 2001). With regard to developing strategies for engineering disulfide bonds, it is important to recognize that a disulfide bond with a favorable position in a local structural environment may markedly increase thermal stability.

Acknowledgments The authors wish to thank Dr. Harumi Fukada of Osaka Prefecture University (Osaka, Japan) for her kind suggestions. X-ray diffraction experiments were carried out with the approval of the Japan Synchrotron Radiation Research Institute (Hyogo, Japan). The experiment of differential scanning calorimetry was carried out by Dr. Harumi Fukada.

Open Access This article is distributed under the terms of the Creative Commons Attribution License which permits any use, distribution, and reproduction in any medium, provided the original author(s) and the source are credited.

\section{References}

Cacciapuoti G, Porcelli M, Bertoldo C, De Rosa M, Zappia V (1994) Purification and characterization of extremely thermophilic and thermostable 5'-methylthioadenosine phosphorylase from the archaeon Sulfolobus solfataricus. Purine nucleoside phosphorylase activity and evidence for intersubunit disulfide bonds. J Biol Chem 269:24762-24769

CCP4 (1994) The CCP4 suite: programs for protein crystallography. Acta Crystallogr D Biol Crystallogr 50:760-763 
Choi IG, Bang WG, Kim SH, Yu YG (1999) Extremely thermostable serine-type protease from Aquifex pyrophilus. Molecular cloning, expression, and characterization. J Biol Chem 274:881-888

Creighton TE (1988) Disulphide bonds and protein stability. BioEssays 8:57-63

Emsley P, Cowtan K (2004) Coot: model-building tools for molecular graphics. Acta Crystallogr D Biol Crystallogr 60:2126-2132

Han ZL, Han SY, Zheng SP, Lin Y (2009) Enhancing thermostability of a Rhizomucor miehei lipase by engineering a disulfide bond and displaying on the yeast cell surface. Appl Microbiol Biotechnol 85:117-126

Hiromi K, Ono S (1963) Time course of consecutive reactions catalyzed by exo-enzymes. J Biochem 53:164-166

Kim HW, Ishikawa K (2010) Structure of hyperthermophilic endocellulase from Pyrococcus horikoshii. Proteins 78:496-500

Kim HW, Ishikawa K (2011) Functional analysis of hyperthermophilic endocellulase from Pyrococcus horikoshii by crystallographic snapshots. Biochem J 437:223-230

Kim HW, Takagi Y, Hagihara Y, Ishikawa K (2007) Analysis of the putative substrate binding region of hyperthermophilic endoglucanase from Pyrococcus horikoshii. Biosci Biotechnol Biochem 71:2585-2587

Ladenstein R, Ren B (2008) Reconsideration of an early dogma, saying "there is no evidence for disulfide bonds in proteins from archaea". Extremophiles 12:29-38

Mansfeld J, Ulbrich-Hofmann R (2007) The stability of engineered thermostable neutral proteases from Bacillus stearothermophilus in organic solvents and detergents. Biotechnol Bioeng 97: 672-679
Mansfeld J, Vriend G, Dijkstra BW, Veltman OR, Van den Burg B, Venema G, Ulbrich-Hofmann R, Eijsink VG (1997) Extreme stabilization of a thermolysin-like protease by an engineered disulfide bond. J Biol Chem 272:11152-11156

Overington JP, Zhu ZY, Sali A, Johnson MS, Sowdhamini R, Louie GV, Blundell TL (1993) Molecular recognition in protein families: a database of aligned-three-dimensional structures of related proteins. Biochem Soc Trans 21(Pt 3):597-604

Richardson JS (1981) The anatomy and taxonomy of protein structure. Adv Protein Chem 34:167-339

Rigden DJ, Woodhead DD, Wong PW, Galperin MY (2011) New structural and functional contexts of the Dx[DN]xDG linear motif: insights into evolution of calcium-binding proteins. PLoS ONE 6:e21507

Schmidt B, Ho L, Hogg PJ (2006) Allosteric disulfide bonds. Biochemistry 45:7429-7433

Toth EA, Worby C, Dixon JE, Goedken ER, Marqusee S, Yeates TO (2000) The crystal structure of adenylosuccinate lyase from Pyrobaculum aerophilum reveals an intracellular protein with three disulfide bonds. J Mol Biol 301:433-450

Turunen O, Etuaho K, Fenel F, Vehmaanpera J, Wu X, Rouvinen J, Leisola M (2001) A combination of weakly stabilizing mutations with a disulfide bridge in the alpha-helix region of Trichoderma reesei endo-1,4-beta-xylanase II increases the thermal stability through synergism. J Biotechnol 88:37-46

Volkin DB, Klibanov AM (1987) Thermal destruction processes in proteins involving cystine residues. J Biol Chem 262:2945-2950 